CARDIOVASCULAR MEDICINE

\title{
Cardiovascular risk factors and clinical presentation in acute coronary syndromes
}

\author{
A Rosengren, L Wallentin, M Simoons, A K Gitt, S Behar, A Battler, D Hasdai
}

Heart 2005;91:1141-1147. doi: 10.1136/hrt.2004.051508

See end of article for authors' affiliations

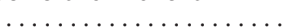

Correspondence to: Dr Annika Rosengren, Department of Medicine, Sahlgrenska University Hospital/Östra, SE-416 85 Goteborg, Śweden; Annika.Rosengren@ hil.gu.se

Accepted

5 November 2004
Objective: To investigate the hypothesis that risk factors may be differently related to severity of acute coronary syndromes (ACS), with ST elevation used as a marker of severe ACS.

Design: Cross sectional study of patients with ACS.

Setting: 103 hospitals in 25 countries in Europe and the Mediterranean basin.

Patients: 10253 patients with a discharge diagnosis of ACS in the Euro heart survey of ACS.

Main outcome measures: Presenting with ST elevation ACS.

Results: Patients with ACS who were smokers had an increased risk to present with ST elevation (age adjusted odds ratio (OR) 1.84, 95\% confidence interval (CI) 1.67 to 2.02). Hypertension (OR $0.65,95 \% \mathrm{Cl}$ 0.60 to 0.70 ) and high body mass index (BMI) ( $p$ for trend 0.0005 ) were associated with less ST elevation ACS. Diabetes mellitus was also associated with less ST elevation, but only among men. Prior disease (infarction, chronic angina, revascularisation) and treatment with aspirin, $\beta$ blockers, or statins before admission were also associated with less ST elevation. After adjustment for age, sex, prior disease, and prior medication, smoking was still significantly associated with increased risk of ST elevation (OR 1.53, $95 \% \mathrm{Cl} 1.38$ to 1.69 ), whereas hypertension was associated with reduced risk (OR $0.75,95 \% \mathrm{Cl} 0.69$ to 0.82 ). Obesity (BMI $>30 \mathrm{~kg} / \mathrm{m}^{2}$ versus $<25 \mathrm{~kg} / \mathrm{m}^{2}$ ) was independently associated with less risk of presenting with ST elevation among women, but not among men.

Conclusion: Among patients with ACS, presenting with ST elevation is strongly associated with smoking, whereas hypertension and high BMI (in women) are associated with less ST elevation, independently of prior disease and medication.
C oronary disease mortality, incidence, and clinical presentation vary greatly over time. In many countries with a high prevalence of coronary heart disease, mortality is now falling rapidly. ${ }^{1-4}$ Concomitantly, there is evidence that acute myocardial infarctions (AMIs) are becoming smaller, ${ }^{5-7}$ and unstable angina pectoris, a less lethal form of the acute coronary syndromes (ACS), now accounts for a substantial proportion of all admissions. ${ }^{8} 9$ Additionally, the mortality from ACS is decreasing more than the incidence, ${ }^{4810}$ with important decreases also in out-ofhospital deaths. ${ }^{211}$ Changes in mortality and incidence have been attributed to changes in coronary care and secondary prevention. ${ }^{12}$ Changes in risk factors may also have a role, ${ }^{13}{ }^{14}$ with falling rates of smoking ${ }^{15}$ and more obesity ${ }^{16}$ in many areas of the world.

Among patients with AMI, those who present with ST elevation develop larger infarctions, have more in-hospital complications, and have higher short term mortality than patients without ST elevation. ${ }^{17}$ Pathophysiologically, patients with ST elevation who progress to Q wave AMI are characterised by occlusive thrombus in the vast majority of cases, ${ }^{18}$ whereas total occlusion is infrequently observed in the early hours of non-Q wave AMI. ${ }^{19}$ Thus, different pathophysiological processes may be involved. We hypothesised that different risk factors, such as smoking and factors associated with obesity (hypertension and diabetes mellitus), may be differently related to different forms of ACS. To this end, we investigated correlates of ST elevation ACS in a large sample of consecutively enrolled patients with ACS.

\section{PATIENTS AND METHODS}

\section{Euro heart survey of acute coronary syndromes}

The details of the Euro heart survey of ACS have been previously described in detail. ${ }^{20}$ The survey was performed in clusters composed of academic and non-academic hospitals and hospitals with and without cardiac catheterisation laboratories and cardiac surgery facilities. During the enrolment period lasting from 4 September 2000 to 15 May 2001, 14271 patients in 25 countries with suspected ACS were screened, of whom 10484 finally had a diagnosis of either AMI or unstable angina pectoris. The locally appointed ethics committees approved the study protocol. Informed consent was obtained from participants if required by the ethics committee, and the study complied with the Declaration of Helsinki. For 231 patients data were missing on either age or sex, leaving 10253 who formed the study population for the present analysis.

For all patients, the tentative initial diagnosis made by the attending physicians was recorded based on the initial ECG pattern: ACS with ST elevation, ACS without ST elevation, and ACS with an undetermined ECG pattern. The full case report form was filled out for patients with a confirmed diagnosis of unstable angina or AMI and categorised according to the discharge diagnosis as either unstable angina, non-Q wave AMI, or Q wave AMI. The survey was conducted through a period when the new definition of AMI had not been uniformly implemented and unstable angina was therefore diagnosed among some patients with slightly increased markers of myocardial necrosis. ${ }^{21}$ For the present study, ST elevation ACS was defined as any presentation with ST elevation.

The case report form detailed the demographic, clinical, and ECG characteristics of the patient, the diagnostic and treatment modalities, the in-hospital complications, and the

Abbreviations: ACS, acute coronary syndromes; $A M I$, acute myocardial infarction; $\mathrm{ARIC}$, atherosclerosis risk in the communities; $\mathrm{BMI}$, body mass index; $\mathrm{Cl}$, confidence interval; $\mathrm{OR}$, odds ratio 
discharge status. Hyperlipidaemia was defined as previously diagnosed by a physician, receiving lipid lowering drugs, or either total cholesterol $>5 \mathrm{mmol} / \mathrm{l}$ or serum triglyceride $>2 \mathrm{mmol} / \mathrm{l}$. Hypertension was defined as previously diagnosed by a physician, receiving medication to lower blood pressure, or known blood pressure $\geqslant 140 \mathrm{~mm} \mathrm{Hg}$ systolic or $\geqslant 90 \mathrm{~mm} \mathrm{Hg}$ diastolic on two or more occasions. Diabetes mellitus was defined as previously diagnosed by a physician. Information on weight and height for the calculation of body mass index (BMI) was taken from patients' records. Current smoking was defined as smoking up to one month before admission. Patients were defined as having no, one, two, or three or more risk factors, based on smoking, diabetes, hypertension, or hyperlipidaemia. Chronic angina was defined as having had angina before at least 30 days before admission. Coronary angiography was done in 5437 (53\%) patients.

\section{Statistical methods}

All analyses were calculated with SAS software version 8e (SAS Institute, Cary, North Carolina, USA). All tests were two sided and $\mathrm{p}<0.05$ were considered significant. The trend for the association between presenting with ST elevation and categorical risk factors was tested with Fisher's exact tests or the Cochran-Armitage trend test. Pearson tests were used for continuous variables. Because BMI data were missing for 1413 patients, many of whom died early, a separate variable was created for missing values for BMI and likewise for patients with no information on smoking $(\mathrm{n}=975)$. BMI was categorised into four groups: 0 , missing data; $1, \leqslant 25 \mathrm{~kg} / \mathrm{m}^{2} ; 2,25-30 \mathrm{~kg} / \mathrm{m}^{2} ;$ and 3 , $\geqslant 30 \mathrm{~kg} / \mathrm{m}^{2}$. Smoking was categorised into three groups: 0 , missing data; 1, non-smokers (including former smokers); and 2, current smokers. For smoking categories 1 to 2, differences in proportions were tested with Fisher's exact tests and with $t$ tests for continuous variables. The trend for the association between categorical risk factors and BMI categories 1-3 was tested with the Cochran-Armitage trend test. Pearson tests were used for continuous variables. Age adjusted odds ratios (ORs), with 95\% confidence intervals (CIs), were calculated by logistic regression with ST elevation ACS as the dependent variable and categories of risk factors as independent variables. We did not adjust for multiple statistical testing because many of the variables that were tested were intercorrelated and to do so would have increased the likelihood of type II error. However, CIs are presented for all main findings. To estimate the independent contribution of each of the variables to the risk of ST elevation ACS, multiple logistic regression models were used. Hyperlipidaemia was not entered into the models because of probable low precision. In a first step, dependent variables that were related to ST elevation in univariate analysis were entered: age, sex, and smoking; prior AMI, chronic angina, and revascularisation; and medication with aspirin or $\beta$ blockers on admission. Because obesity is strongly causally related to hypertension and diabetes they were added only in a second model to investigate the effect of obesity without

Table 1 Discharge diagnosis by presence or absence of ST elevation

\begin{tabular}{llll}
\hline & $\begin{array}{l}\text { ACS with ST } \\
\text { elevation } \\
\text { (n=4361) }\end{array}$ & $\begin{array}{l}\text { ACS without ST } \\
\text { elevation } \\
(\mathbf{n}=5892)\end{array}$ & $\begin{array}{l}\text { All } \\
(\mathbf{n}=10253)\end{array}$ \\
\hline Q wave MI & $2822(65 \%)$ & $541(9 \%)$ & $3363(33 \%)$ \\
Non-Q wave MI & $968(22 \%)$ & $1600(27 \%)$ & $2568(25 \%)$ \\
Unstable angina & $571(13 \%)$ & $3751(64 \%)$ & $4322(42 \%)$ \\
\hline ACS, acute coronary syndromes; MI, myocardial infarction.
\end{tabular}

these intermediary factors. Use of statins was consistently not significant $(\mathrm{p}>0.15$ in all models) and was not included. In addition, separate models were created for men and women. Possible interactions between sex and smoking were tested with logistic regression, with the interaction term (sex*smoking) introduced in the logistic regression model with ST elevation as the dependent variable. We also included, separately, similar interaction terms for other variables where a possible interaction was detected.

\section{RESULTS}

Of the patients enrolled in the survey, $43 \%$ presented with ST elevation (table 1). Of patients with ST elevation, 65\% were discharged with a diagnosis of Q wave MI and 13\% with unstable angina. Fifty seven per cent presented without ST elevation; of these $9 \%$ were discharged with a diagnosis of $\mathrm{Q}$ wave MI and $64 \%$ with unstable angina.

Table 2 shows baseline risk factors and prior disease for all patients in the study and separated for patients with and without ST elevation. Overall, the prevalence of risk factors was high, with only $12 \%$ of the total study population not having any of the predefined risk factors (smoking, hypertension, hyperlipidaemia, or diabetes mellitus). Twenty four per cent had known diabetes mellitus, 58\% had hypertension, $47 \%$ had hyperlipidaemia, and 30\% were smokers. BMI was not recorded in 14\%; of the remainder, $68 \%$ were overweight or obese. Patients with ST elevation were younger and more were men and current smokers. They had a lower prevalence of other risk factors, less prior disease, and fewer medications.

In subsequent analyses, categories of risk factors and prior disease were compared for the proportion of patients with ST elevation (table 3). The proportion of patients with ST elevation was higher among current smokers than nonsmokers (OR 1.84, 95\% CI 1.67 to 2.02). The OR associated with smoking was higher in women than in men, with a formal test for interaction significant $(\mathrm{p}$ for interaction 0.0098). Obesity (OR 0.76, 95\% CI 0.67 to 0.85 for BMI $>30 \mathrm{~kg} / \mathrm{m}^{2} v<25 \mathrm{~kg} / \mathrm{m}^{2}$ ) and hypertension (OR 0.65, 95\% CI .60 to 0.70 ) were associated with less risk of presenting with ST elevation. Diabetes mellitus carried less risk of presenting with ST elevation among men but not among women ( $\mathrm{p}$ for interaction 0.0004). There was also a significant interaction between sex and BMI $(p=0.015)$, with a stronger effect among women than among men. Prior AMI, revascularisation, or chronic angina and treatment with aspirin, $\beta$ blockers, or statins before hospitalisation were all associated with lower risk of presenting with ST elevation in both men and women.

Of the smokers in the study population, $73 \%$ were below 65 years and $18 \%$ were women compared with $35 \%$ and $40 \%$, respectively, among the non-smokers (table 4). Smokers had lower BMI but, although significant, the absolute difference was small. They also had less diabetes mellitus, hypertension, prior disease, and medication on admission. Compared with patients with normal weight (BMI $<25 \mathrm{~kg} / \mathrm{m}^{2}$ ), slightly more of the obese patients were women. Obese patients were also younger and had more hypertension, diabetes mellitus, and hyperlipidaemia (table 5). The prevalence of prior AMI, chronic angina, and revascularisation was by and large similar, regardless of BMI category, but obese patients tended to take more medications.

To investigate the relative contribution of risk factors adjusted for age, prior disease, and medication of admission, multiple logistic regression analyses were done with ST elevation as the dependent variable (table 6). In a first analysis we considered only smoking, BMI, and prior disease and medication, but not hypertension or diabetes because obesity is strongly causally related to these factors. After 
Table 2 Baseline risk factors and prior disease by presence or absence of ST elevation in the Euro heart survey of ACS

\begin{tabular}{|c|c|c|c|c|}
\hline & $\begin{array}{l}\text { ACS with ST elevation } \\
(n=4361)\end{array}$ & $\begin{array}{l}\text { ACS without ST } \\
\text { elevation }(n=5892)\end{array}$ & p Value & $\begin{array}{l}\text { All } \\
\text { ( } n=10253\end{array}$ \\
\hline Age $<65$ & $2280(52 \%)$ & $2439(41 \%)$ & $<0.0001$ & $4719(46 \%)$ \\
\hline Women & $1239(28 \%)$ & $2090(35 \%)$ & $<0.0001$ & $3329(32 \%)$ \\
\hline \multicolumn{5}{|l|}{ Risk factors } \\
\hline \multicolumn{5}{|l|}{ BMI $\left(\mathrm{kg} / \mathrm{m}^{2}\right)$} \\
\hline Not recorded & $472(11 \%)$ & 941 (16\%) & & $1413(14 \%$ \\
\hline Normal $(<25)$ & $1294(30 \%)$ & $1502(25 \%)$ & & $2796(27 \%)$ \\
\hline Overweight $(25-30)$ & 1807 (41\%) & 2322 (39\%) & & $4129(40 \%)$ \\
\hline Obese $(>30)$ & $788(18 \%)$ & 1127 (19\%) & $0.0005^{*}$ & 1915 (19\%) \\
\hline Diabetes mellitus & $969(22 \%)$ & $1470(25 \%)$ & 0.001 & $2439(24 \%)$ \\
\hline Hypertension & $2215(51 \%)$ & $3710(63 \%)$ & $<0.0001$ & $5925(58 \%)$ \\
\hline Hyperlipidaemia & $1859(43 \%)$ & 2997 (51\%) & $<0.0001$ & $4856(47 \%)$ \\
\hline \multicolumn{5}{|l|}{ Smoking } \\
\hline Not recorded & $423(10 \%)$ & $552(9 \%)$ & & $975(10 \%)$ \\
\hline Non-smoker† & $2252(52 \%)$ & $3933(67 \%)$ & & $6185(60 \%)$ \\
\hline Current smoker & 1686 (39\%) & $1407(24 \%)$ & $<0.0001 \dagger$ & $3093(30 \%)$ \\
\hline \multicolumn{5}{|l|}{ Number of risk factors $\ddagger \S$} \\
\hline 0 & $580(13 \%)$ & 699 (12\%) & & $1279(12 \%)$ \\
\hline 1 & $1644(38 \%)$ & $1980(34 \%)$ & & $3624(35 \%)$ \\
\hline 2 & $1471(34 \%)$ & $2177(37 \%)$ & & $3648(36 \%)$ \\
\hline$\geqslant 3$ & $666(15 \%)$ & $1036(18 \%)$ & $<0.0001$ & $1702(17 \%)$ \\
\hline \multicolumn{5}{|c|}{ Prior diseases and medication before admission } \\
\hline MI & $962(22 \%)$ & $2142(36 \%)$ & $<0.0001$ & $3104(30 \%)$ \\
\hline Chronic angina & $921(21 \%)$ & $2193(37 \%)$ & $<0.0001$ & $3114(30 \%)$ \\
\hline Revascularisation & $414(9 \%)$ & $1308(22 \%)$ & $<0.0001$ & $1722(17 \%)$ \\
\hline Aspirin & $1320(30 \%)$ & $2978(51 \%)$ & $<0.0001$ & $4298(42 \%)$ \\
\hline$\beta$ Blocker & $1089(25 \%)$ & $2292(39 \%)$ & $<0.0001$ & $3381(33 \%)$ \\
\hline Statin & $656(15 \%)$ & $1424(24 \%)$ & $<0.0001$ & $2080(20 \%)$ \\
\hline \multicolumn{5}{|c|}{$\begin{array}{l}\text { *Trend test, only among patients with recorded height and weight. } \\
\text { †lncludes former smokers. } \\
\text { fOnly among patients with complete data for smoking. } \\
\text { SRisk factors: smoking, hypertension, diabetes, hyperlipidaemia. } \\
\text { BMI, body mass index. }\end{array}$} \\
\hline
\end{tabular}

adjustment for all other variables in the model smoking was still associated with increased risk of ST elevation (OR 1.34, 95\% CI 1.20 to 1.50 among men and OR 2.31 , 95\% CI 1.87 to 2.85 among women). Obesity was associated with lower risk of presenting with ST elevation (OR $0.84,95 \%$ CI 0.75 to $0.96)$. When analysed by sex, obese women, but not obese men, had a lower risk of ST elevation than did women and men with normal weight (OR $0.75,95 \%$ CI 0.61 to 0.93 , and OR $0.90,95 \%$ CI 0.77 to 1.05 , respectively). Prior AMI, chronic angina, prior revascularisation, and aspirin and $\beta$ blocker use before admission were all independently associated with less ST elevation. If BMI was analysed as a continuous variable, among the 8855 patients with recorded weight and height, risk of ST elevation was significantly reduced with increasing BMI overall $(p=0.0001 ; p=0.0505$ among men, $\mathrm{p}=0.0008$ among women).

In a second model that included hypertension and diabetes, obesity was not overall significantly associated with ST elevation (OR $0.88,95 \%$ CI 0.78 to 1.00 ), although risk reduction among women was still significant (OR 0.77, 95\% CI 0.62 to 0.96). If BMI was analysed as a continuous variable, risk of ST elevation was still significantly reduced with increasing BMI overall ( $\mathrm{p}=0.0018$ ) but only among women $(p=0.001)$, not among men $(p=0.27)$. Hypertension was associated with less risk of ST elevation (OR $0.77,95 \%$ CI 0.70 to 0.86 for men, and OR $0.70,95 \%$ CI 0.60 to 0.83 for women). After adjustment, diabetes was no longer significantly associated with less risk of ST elevation among men, whereas women with diabetes had increased risk (OR $1.38,95 \%$ CI 1.16 to 1.62 ).

\section{DISCUSSION}

In this large survey of patients with ACS from Europe and the Mediterranean area, where only a small proportion of patients had no conventional risk factors, we found that presenting with ST elevation was strongly associated with smoking but inversely related to BMI and hypertension. Prior manifestations of coronary disease, with concomitant treatment, were associated with less ST elevation, but the associations between presenting with ST elevation and risk factors were independent of prior disease and medication. Thus, shifts in coronary risk factor pattern, with reduced smoking rates and an increase in the prevalence of obesity and obesity related disorders such as hypertension, may be contributing to a shift in the clinical presentation in ACS and perhaps to improved outcomes.

Several studies have reported decreasing severity of AMI and ACS. ${ }^{5-722}$ In a study from Finland, the proportion of patients who had an AMI with definite ECG findings decreased by about one third between 1983 and 1990, ${ }^{22}$ together with a significant decrease in the incidence of increased cardiac enzymes. In the US based ARIC (atherosclerosis risk in the communities) study, mean peak creatine kinase concentration decreased 5\% per year between 1987 and 1994 among patients with ACS; however, at the same time the proportion with ST elevation increased, providing mixed support for decreases in the severity of AMI. ${ }^{6}$ Nonetheless, two other population based studies from the USA have indicated decreased disease severity in AMI. One study showed that the proportion of Q wave AMIs, as part of all AMIs, decreased from about one half to one third from the mid 1980s to the mid 1990s. ${ }^{5}$ The other study, from Olmsted County, Minnesota, examined several indicators of AMI severity between 1983 and 1994. The proportion of patients presenting with ST elevation declined, as well as the occurrence of Q waves and peak creatine kinase concentrations, independently of time to presentation and differences in reperfusion treatment. ${ }^{7}$

Contributing to the evidence of less severe AMIs are the numerous studies that report decreasing mortality from 
Table 3 Age adjusted odds ratios for risk factors and prior disease associated with ST elevation among men and women in the Euro heart survey of ACS

\begin{tabular}{|c|c|c|c|c|c|c|c|}
\hline & \multirow[b]{2}{*}{ Total } & \multicolumn{2}{|l|}{ All (4361) } & \multicolumn{2}{|l|}{ Men (3122) } & \multicolumn{2}{|c|}{ Women (1239) } \\
\hline & & $\begin{array}{l}\text { ST elevation } \\
\text { ACS }\end{array}$ & OR $(95 \% \mathrm{Cl})$ & $\begin{array}{l}\text { ST elevation } \\
\text { ACS }\end{array}$ & OR $(95 \% \mathrm{Cl})$ & $\begin{array}{l}\text { ST elevation } \\
\text { ACS }\end{array}$ & OR $(95 \% \mathrm{Cl})$ \\
\hline \multicolumn{8}{|l|}{ Age (years) } \\
\hline$<65$ & 4719 & $2280(48 \%)$ & 1.00 & $1887(51 \%)$ & 1.00 & $393(39 \%)$ & 1.00 \\
\hline$\geqslant 65$ & 5534 & 2081 (38\%) & $0.65(0.60$ to 0.70$)$ & 1235 (38\%) & $0.60(0.55$ to 0.66$)$ & $846(36 \%)$ & $0.90(0.77$ to 1.05$)$ \\
\hline \multicolumn{8}{|l|}{ BMI $\left(\mathrm{kg} / \mathrm{m}^{2}\right)$} \\
\hline Not recorded & 1413 & $472(33 \%)$ & $0.62(0.55$ to 0.71$)$ & $310(37 \%)$ & 0.71 (0.60 to 0.84$)$ & $162(28 \%)$ & $0.49(0.40$ to 0.62$)$ \\
\hline$<25 \mathrm{~kg} / \mathrm{m}^{2}$ & 2796 & $1294(46 \%)$ & 1.00 & $880(47 \%)$ & 1.00 & $414(44 \%)$ & 1.00 \\
\hline $25-30 \mathrm{~kg} / \mathrm{m}^{2}$ & 4129 & $1807(44 \%)$ & $0.87(0.78$ to 0.95$)$ & $1399(46 \%)$ & 0.91 (0.81 to 1.02 ) & $408(38 \%)$ & $0.76(0.63$ to 0.90$)$ \\
\hline$>30 \mathrm{~kg} / \mathrm{m}^{2}$ & 1915 & $788(41 \%)$ & $0.76(0.67$ to 0.85$)$ & $533(45 \%)$ & 0.82 (0.71 to 0.95$)$ & $255(35 \%)$ & $0.68(0.55$ to 0.83$)$ \\
\hline BMI $\left(\text { per } \mathrm{kg} / \mathrm{m}^{2}\right)^{*}$ & & & $0.97(0.96$ to 0.98$)$ & & 0.98 (0.97 to 0.99$)$ & & 0.96 (0.95 to 0.98$)$ \\
\hline \multicolumn{8}{|l|}{ Smoking } \\
\hline Missing data & 975 & $423(43 \%)$ & 1.37 (1.20 to 1.57$)$ & $290(45 \%)$ & 1.34 (1.13 to 1.58$)$ & $133(41 \%)$ & 1.41 (1.11 to 1.78$)$ \\
\hline No & 6185 & $2252(36 \%)$ & 1.00 & $1452(39 \%)$ & 1.00 & $800(33 \%)$ & 1.00 \\
\hline Yes & 3093 & $1686(55 \%)$ & 1.84 (1.67 to 2.02$)$ & 1380 (54\%) & $1.60(1.43$ to 1.79$)$ & $306(55 \%)$ & $2.65(2.16$ to 3.24$)$ \\
\hline \multicolumn{8}{|l|}{ Hypertension } \\
\hline No & 4328 & $2146(50 \%)$ & 1.00 & 1664 (51\%) & 1.00 & $482(45 \%)$ & 1.00 \\
\hline Yes & 5925 & $2215(37 \%)$ & 0.65 (0.60 to 0.70$)$ & $1458(40 \%)$ & 0.68 (0.61 to 0.74$)$ & 757 (34\%) & $0.62(0.54$ to 0.72$)$ \\
\hline \multicolumn{8}{|l|}{ Diabetes mellitus } \\
\hline No & 7814 & $3392(43 \%)$ & 1.00 & $2529(46 \%)$ & 1.00 & $863(37 \%)$ & 1.00 \\
\hline Yes & 2439 & $969(40 \%)$ & $0.92(0.83$ to 1.01$)$ & $593(40 \%)$ & 0.83 (0.74 to 0.94$)$ & $376(39 \%)$ & $1.12(0.96$ to 1.30$)$ \\
\hline \multicolumn{8}{|l|}{ Prior MI } \\
\hline No & 7149 & $3399(48 \%)$ & 1.00 & $2420(51 \%)$ & 1.00 & $979(41 \%)$ & 1.00 \\
\hline Yes & 3104 & $962(31 \%)$ & $0.52(0.48$ to 0.57$)$ & $702(32 \%)$ & $0.48(0.43$ to 0.54$)$ & $260(28 \%)$ & $0.59(0.50$ to 0.69$)$ \\
\hline \multicolumn{8}{|l|}{ Chronic angina } \\
\hline No & 7139 & $3440(48 \%)$ & 1.00 & $2487(50 \%)$ & 1.00 & $953(43 \%)$ & 1.00 \\
\hline Yes & 3114 & $921(30 \%)$ & $0.47(0.43$ to 0.52$)$ & $635(32 \%)$ & $0.49(0.44$ to 0.55$)$ & $286(25 \%)$ & $0.45(0.38$ to 0.53$)$ \\
\hline \multicolumn{8}{|c|}{ Prior revascularisation } \\
\hline No & 8531 & $3947(46 \%)$ & 1.00 & $2804(50 \%)$ & 1.00 & $1143(39 \%)$ & 1.00 \\
\hline Yes & 1722 & $414(24 \%)$ & $0.36(0.32$ to 0.40$)$ & $318(24 \%)$ & $0.33(0.28$ to 0.37$)$ & $96(23 \%)$ & $0.46(0.36$ to 0.58$)$ \\
\hline \multicolumn{8}{|c|}{ ASA before admission } \\
\hline No & 5955 & 3041 (51\%) & 1.00 & $2188(54 \%)$ & 1.00 & $853(45 \%)$ & 1.00 \\
\hline Yes & 4298 & $1320(31 \%)$ & $0.45(0.41$ to 0.49$)$ & $934(33 \%)$ & $0.44(0.40$ to 0.49$)$ & $386(27 \%)$ & $0.46(0.40$ to 0.53$)$ \\
\hline \multicolumn{8}{|c|}{$\beta$ Blocker before admission } \\
\hline No & 6872 & $3272(48 \%)$ & 1.00 & $2352(50 \%)$ & 1.00 & $920(42 \%)$ & 1.00 \\
\hline Yes & 3381 & 1089 (32\%) & $0.53(0.49$ to 0.58$)$ & $770(34 \%)$ & $0.53(0.47$ to 0.58$)$ & $319(28 \%)$ & $0.56(0.48$ to 0.65$)$ \\
\hline \multicolumn{8}{|c|}{ Statin before admission } \\
\hline No & 8173 & $3705(45 \%)$ & 1.00 & $2659(48 \%)$ & 1.00 & $1046(39 \%)$ & 1.00 \\
\hline Yes & 2080 & $656(32 \%)$ & $0.54(0.49$ to 0.60$)$ & $463(32 \%)$ & 0.50 (0.44 to 0.57$)$ & $193(30 \%)$ & $0.65(0.54$ to 0.78$)$ \\
\hline
\end{tabular}

coronary disease in the USA, ${ }^{8}$ Australia, ${ }^{2}$ and in large parts of Europe $^{3}$ and reports of decreasing case fatality. ${ }^{11}{ }^{23}$ In studies investigating trends in fatal and non-fatal AMI, several studies have found that mortality decreased more than the incidence..$^{4}{ }^{10}$ The increasing survival of patients admitted to hospital has generally been attributed to better hospital care, but changes in risk factor patterns have also been implicated. ${ }^{4}$ Trends in out-of-hospital coronary mortality probably reflect changes in cardiovascular risk factors, whereas in-hospital mortality is more tied to medical care. However, judging from the results of the present study, and because ST elevation has the most adverse short term prognosis, it is possible that inhospital mortality is also influenced by risk factor pattern.

Overall, the prevalence of risk factors was high in the Euro heart survey of ACS, with only $12 \%$ of the men and women lacking any of the conventional risk factors for the disease.

Table 4 Baseline risk factors and prior disease in smokers and non-smokers in the Euro heart survey of ACS

\begin{tabular}{|c|c|c|c|c|}
\hline & $\begin{array}{l}\text { Smokers } \\
(\mathrm{n}=3093)\end{array}$ & $\begin{array}{l}\text { Non-smokers } \\
(n=6185)\end{array}$ & $p$ Value & $\begin{array}{l}\text { No data } \\
(\mathrm{n}=975)\end{array}$ \\
\hline Women & $558(18 \%)$ & $2445(40 \%)$ & $<0.0001$ & $326(33 \%)$ \\
\hline Age (years)* & $57.0(11.4)$ & 68.0 (11.3) & $<0.0001$ & $70.0(11.7)$ \\
\hline Age $<65$ & $2262(73 \%)$ & $2173(35 \%)$ & & $284(29 \%)$ \\
\hline \multicolumn{5}{|l|}{ Risk factors } \\
\hline BMI $\left(\mathrm{kg} / \mathrm{m}^{2}\right)^{*}$ & $26.9(4.3)$ & $27.3(4.2)$ & $<0.0001$ & $27.1(4.0)$ \\
\hline Diabetes mellitus & $510(16 \%)$ & $1665(27 \%)$ & $<0.0001$ & $264(27 \%)$ \\
\hline Hypertension & $1404(45 \%)$ & $3962(64 \%)$ & $<0.0001$ & $559(57 \%)$ \\
\hline Hyperlipidaemia & $1465(47 \%)$ & 3031 (49\%) & 0.14 & $360(37 \%)$ \\
\hline \multicolumn{5}{|c|}{ Prior diseases and medication before admission } \\
\hline MI & $672(22 \%)$ & 2080 (34\%) & $<0.0001$ & $352(36 \%)$ \\
\hline Chronic angina & $676(22 \%)$ & 2103 (34\%) & $<0.0001$ & $335(34 \%)$ \\
\hline Revascularisation & 337 (11\%) & 1199 (19\%) & $<0.0001$ & $186(19 \%)$ \\
\hline ASA & $950(31 \%)$ & $2887(47 \%)$ & $<0.0001$ & $471(48 \%)$ \\
\hline$\beta$ Blocker & $781(25 \%)$ & 2197 (36\%) & $<0.0001$ & $403(41 \%)$ \\
\hline Statin & $507(16 \%)$ & $1365(22 \%)$ & $<0.0001$ & $208(21 \%)$ \\
\hline
\end{tabular}


Table 5 Baseline risk factors and prior disease by categories of BMl in the Euro heart survey of ACS

\begin{tabular}{|c|c|c|c|c|c|}
\hline & \multicolumn{3}{|l|}{ BMI $\left(\mathrm{kg} / \mathrm{m}^{2}\right)$} & \multirow[b]{2}{*}{$\mathrm{p}$ Value } & \multirow[b]{2}{*}{$\begin{array}{l}\text { No data } \\
(n=1413)\end{array}$} \\
\hline & $\begin{array}{l}<25 \\
(n=2796)\end{array}$ & $\begin{array}{l}25-30 \\
(n=4129)\end{array}$ & $\begin{array}{l}>30 \\
(n=1915)\end{array}$ & & \\
\hline Women & $937(34 \%)$ & $1085(26 \%)$ & $724(38 \%)$ & 0.001 & $583(42 \%)$ \\
\hline Age $<65$ & $1173(42 \%)$ & $2062(50 \%)$ & $1049(55 \%)$ & & $435(31 \%)$ \\
\hline $\begin{array}{l}\text { Age (years)* } \\
\text { Risk factors }\end{array}$ & 65.8 (13.3) & 63.7 (11.9) & $62.4(11.5)$ & $<0.0001$ & $69.8(12.7)$ \\
\hline \multicolumn{3}{|l|}{ Risk factors } & & $<0.0001$ & \\
\hline Hypertension & $1378(49 \%)$ & $2422(59 \%)$ & $1347(70 \%)$ & $<0.0001$ & $778(55 \%)$ \\
\hline Hyperlipidaemia & $1206(43 \%)$ & $2046(50 \%)$ & 1020 (53\%) & $<0.0001$ & $584(41 \%)$ \\
\hline Missing data for smoking & $213(8 \%)$ & $301(7 \%)$ & $146(8 \%)$ & & $315(22 \%)$ \\
\hline Current smoker & $971(35 \%)$ & $1278(31 \%)$ & $561(29 \%)$ & 0.006 & $283(20 \%)$ \\
\hline \multicolumn{6}{|c|}{ Prior diseases and medication before admission } \\
\hline Ml & $809(29 \%)$ & $1248(30 \%)$ & $576(30 \%)$ & 0.60 & $471(33 \%)$ \\
\hline Chronic angina & $799(29 \%)$ & $1268(31 \%)$ & $590(31 \%)$ & 0.072 & $457(32 \%)$ \\
\hline Revascularisation & $435(16 \%)$ & $726(18 \%)$ & $328(17 \%)$ & 0.074 & $233(16 \%)$ \\
\hline ASA & $1100(39 \%)$ & $1741(42 \%)$ & 825 (43\%) & 0.010 & $632(45 \%)$ \\
\hline$\beta$ Blocker & $853(31 \%)$ & $1365(33 \%)$ & $692(36 \%)$ & 0.0001 & $471(33 \%)$ \\
\hline Statin & $499(18 \%)$ & $884(21 \%)$ & $407(21 \%)$ & 0.009 & $290(21 \%)$ \\
\hline
\end{tabular}

This is a lower proportion than in the dataset from 14 international randomised clinical trials reported by Khot et $a l,{ }^{24}$ probably in part because patients taking part in trials are selected. Even so, the proportion with no risk factors is probably underestimated because some patients with diabetes, hyperlipidaemia, or hypertension may be unaware of these conditions. Few studies have investigated risk factors in relation to the various manifestations of ACS. Although Khot et $a l^{24}$ did not comment on this, in their study current smoking was more prevalent among patients with ST elevation AMI than among patients with non-ST elevation
AMI or unstable angina, particularly among women, whereas hypertension was more common among patients with nonST elevation AMI. In a recent study of women hospitalised with AMI or unstable angina, current cigarette smoking (OR 1.60) and diabetes mellitus (OR 1.44) predicted AMI, whereas prior coronary disease (OR 0.70 ) independently predicted unstable angina. ${ }^{25}$ Other studies have also found smoking to be more prevalent among patients with ST elevation AMI. ${ }^{26}{ }^{27}$ Paradoxically, smoking has been found to be associated with lower short term mortality among patients admitted with AMI, particularly after thrombolysis..28-30

Table 6 Multivariate age adjusted odds ratios (with 95\% Cl) for risk factors and prior disease associated with ST elevation among men and women in the Euro heart survey of ACS

\begin{tabular}{|c|c|c|c|}
\hline & All & Men & Women \\
\hline \multicolumn{4}{|l|}{ Model I } \\
\hline \multicolumn{4}{|l|}{ BMI $\left(\mathrm{kg} / \mathrm{m}^{2}\right)$} \\
\hline Not recorded & $0.62(0.54$ to 0.71$)$ & $0.71(0.59$ to 0.84$)$ & $0.48(0.38$ to 0.60$)$ \\
\hline Overweight $(25-30)$ & 0.92 (0.83 to 1.02 ) & $0.98(0.87$ to 1.11$)$ & $0.83(0.69$ to 1.00$)$ \\
\hline Obese $(>30)$ & $0.84(0.75$ to 0.96$)$ & $0.90(0.77$ to 1.05$)$ & $0.75(0.61$ to 0.93$)$ \\
\hline Missing data for smoking & $1.52(1.32$ to 1.76$)$ & $1.46(1.22$ to 1.75$)$ & $1.66(1.29$ to 2.13$)$ \\
\hline Current smoker & $1.53(1.38$ to 1.69$)$ & $1.34(1.20$ to 1.50$)$ & $2.31(1.87$ to 2.85$)$ \\
\hline \multicolumn{4}{|c|}{ Prior diseases and medication before admission } \\
\hline MI & $0.82(0.74$ to 0.91$)$ & $0.78(0.69$ to 0.89$)$ & $0.93(0.77$ to 1.12$)$ \\
\hline Chronic angina & $0.60(0.55$ to 0.66$)$ & $0.64(0.57$ to 0.72$)$ & $0.55(0.47$ to 0.65$)$ \\
\hline Revascularisation & $0.56(0.49$ to 0.64$)$ & $0.52(0.44$ to 0.60$)$ & $0.72(0.55$ to 0.93$)$ \\
\hline ASA & $0.66(0.59$ to 0.73$)$ & $0.67(0.60$ to 0.76$)$ & $0.63(0.53$ to 0.74$)$ \\
\hline$\beta$ Blocker & $0.83(0.75$ to 0.92$)$ & $0.86(0.76$ to 0.97$)$ & $0.77(0.64$ to 0.91$)$ \\
\hline \multicolumn{4}{|l|}{$\begin{array}{l}\text { Model II } \\
\mathrm{BMI}\left(\mathrm{kg} / \mathrm{m}^{2}\right)\end{array}$} \\
\hline Not recorded & $0.62(0.54$ to 0.71$)$ & $0.71(0.60$ to 0.85$)$ & $0.47(0.37$ to 0.59$)$ \\
\hline Overweight $(25-30)$ & $0.94(0.85$ to 1.04$)$ & $1.01(0.89$ to 1.14$)$ & $0.84(0.69$ to 1.01$)$ \\
\hline Obese $(>30)$ & $0.88(0.78$ to 1.00$)$ & $0.96(0.82$ to 1.12$)$ & $0.77(0.62$ to 0.96$)$ \\
\hline Diabetes mellitus & $1.10(1.00$ to 1.22$)$ & $0.97(0.86$ to 1.10$)$ & $1.38(1.16$ to 1.62$)$ \\
\hline Hypertension & 0.75 (0.69 to 0.82$)$ & $0.77(0.70$ to 0.86$)$ & $0.70(0.60$ to 0.83$)$ \\
\hline Smoking not recorded & $1.50(1.29$ to 1.73$)$ & $1.44(1.21$ to 1.73$)$ & $1.63(1.27$ to 2.10$)$ \\
\hline Current smoker & 1.50 (1.35 to 1.65$)$ & $1.31(1.17$ to 1.47$)$ & $2.27(1.83$ to 2.80$)$ \\
\hline \multicolumn{4}{|c|}{ Prior diseases and medication before admission } \\
\hline MI & $0.82(0.74$ to 0.91$)$ & $0.79(0.70$ to 0.89$)$ & $0.90(0.75$ to 1.09$)$ \\
\hline Chronic angina & $0.61(0.56$ to 0.67$)$ & 0.65 (0.58 to 0.73$)$ & $0.56(0.47$ to 0.66$)$ \\
\hline Revascularisation & $0.56(0.49$ to 0.64$)$ & $0.52(0.44$ to 0.60$)$ & $0.70(0.54$ to 0.92$)$ \\
\hline ASA & 0.65 (0.59 to 0.72$)$ & $0.67(0.59$ to 0.76$)$ & $0.62(0.52$ to 0.74$)$ \\
\hline$\beta$ Blocker & $0.86(0.78$ to 0.95$)$ & $0.88(0.78$ to 1.00$)$ & $0.80(0.67$ to 0.95$)$ \\
\hline \multicolumn{4}{|c|}{$\begin{array}{l}\text { In model I the effect of increasing } B M I \text { is assessed without intermediary variables (diabetes and hypertension). In } \\
\text { model II these variables are added. If } B M I \text { was analysed as a continuous variable in model I, among the } 8855 \\
\text { patients with recorded weight and height, risk of ST elevation was significantly reduced with increasing BMl overal } \\
\text { ( } p=0.0001 ; p=0.0505 \text { among men, } p=0.0008 \text { among women). Corresponding } p \text { values for model II were } \\
p=0.0018 \text { overall, among men } p=0.27 \text {, among women } p=0.001 \text {. }\end{array}$} \\
\hline
\end{tabular}


Smoking is associated with a hypercoagulable state, particularly with respect to increased concentrations of plasma fibrinogen, ${ }^{31} 32$ but the propensity for intracoronary clot formation associated with smoking is also due to effects on platelet activation. ${ }^{32}$ Smokers have also been shown to have better outcome in ACS without ST elevation, but this was shown to be due to a more favourable clinical profile. ${ }^{33}$

The role of obesity in ACS is much less clear. Obesity is a risk factor for $\mathrm{AMI}^{34}$ but is also strongly associated with other factors in the development of coronary disease, such as hypertension, diabetes mellitus, and decreased glucose tolerance, as well as dyslipidaemia and inflammation. We found that BMI was inversely related to the risk of ST elevation but also that this effect was attenuated if correlates of obesity such as hypertension and diabetes (among men) were taken into account, indicating that the association between BMI and ST elevation was partly mediated by these intermediary factors. The effect was significant only among the women in the study. Among patients with stable and unstable coronary disease undergoing coronary angiography, obesity was recently shown to be strongly related to instability, independently of correlated risk factors and markers of inflammation. ${ }^{35}$ How this relates to our finding of less ST elevation in obese patients is not clear.

Hypertension is common among patients with AMI and unstable angina, but not many studies have evaluated the role of hypertension in patients with ACS. One recent study showed that more hypertensive patients with ACS were women and that they were older, had more co-morbidities, ${ }^{36}$ and slightly less often had AMI diagnosed. Hypertensive patients have also been shown to have more non-Q wave AMI but similar infarct sizes compared with non-hypertensive patients. ${ }^{37}$

The findings from the present study may tentatively help to explain the changes in clinical presentation of ACS in parts of the world. Decreasing rates of smoking, particularly among men, may be resulting in a lower proportion of patients presenting with ST elevation. The worldwide epidemic of overweight and obesity may be counteracting the beneficial effect of the decreasing trends in smoking but may be resulting in milder coronary events, with lower short term mortality. However, despite the increasing trend worldwide of overweight and obesity, blood pressure levels have decreased over the past decades in some countries, ${ }^{38}$ illustrating the complexity of these issues.

\section{Limitations}

AMI and unstable angina diagnoses were not strictly validated. Even though atherosclerosis is probably the main causative factor for ACS even in patients without an angiographically obvious coronary stenosis, a proportion of the patients with diagnosed unstable angina may have had chest pain of non-cardiac origin. However, among the 5437 patients in the study who underwent a coronary angiography only $5 \%$ of these were normal. Only a small minority of patients with a diagnosis of unstable angina and no ST elevation had no prior cardiovascular disease or diabetes. Accordingly, the proportion of patients without any form of coronary disease is likely to be low. Limiting our analysis to patients with confirmed AMI or angiographically confirmed coronary disease would have excluded an important subset of the ACS population.

\section{Conclusions}

The main finding of this large survey of patients with ACS from 25 countries in Europe and the Mediterranean basin was that different risk factors were related to different ACS diagnoses. Smoking was related to patients presenting with ST elevation, whereas obesity and hypertension were more common among patients who presented without ST elevation. These differences suggest variations in pathophysiology associated with risk factor pattern, but they may also help to explain some of the temporal trends with respect to disease severity and decreasing mortality from coronary disease in areas where the epidemic of coronary disease seems to be receding.

The Euro heart survey of acute coronary syndromes was sponsored by Schering-Plough and Centocor. The Swedish participation was supported by the Swedish Heart and Lung Foundation.

\section{Authors' affiliations}

A Rosengren, Sahlgrenska University Hospital/Östra, Goteborg,

Sweden

L Wallentin, University Hospital, Uppsala, Sweden

M Simoons, Thoraxcentre, Rotterdam, the Netherlands

A K Gitt, Klinikum der Stadt Ludwigshafen, Ludwigshafen, Germany

S Behar, D Hasdai, Neufeld Cardiac Research Institute, Tel-Hashomer, Israel

A Battler, Rabin Medical Center, Petah Tikva, Israel

Conflict of interest: none

The locally appointed ethics committees approved the study protocol, informed consent was obtained from participants if required by the ethics committee, and the study was done in compliance with the Declaration of Helsinki.

\section{REFERENCES}

1 Abildstrom SZ, Rasmussen S, Rosen M, et al. Trends in incidence and case fatality rates of acute myocardial infarction in Denmark and Sweden. Heart 2003;89:507-11

2 Beaglehole R, Stewart AW, Jackson R, et al. Declining rates of coronary heart disease in New Zealand and Australia, 1983-1993. Am J Epidemiol 1997;145:707-13.

3 Sans S, Kesteloot H, Kromhout D. The burden of cardiovascular diseases mortality in Europe. Task Force of the European Society of Cardiology on Cardiovascular Mortality and Morbidity Statistics in Europe. Eur Heart J 1997; 18:1231-48.

4 Volmink JA, Newton JN, Hicks NR, et al. Coronary event and case fatality rates in an English population: results of the Oxford myocardial infarction incidence study. The Oxford myocardial infarction incidence study group. Heart 1998;80:40-4.

5 Daverman HL, Lessard D, Yarzebski J, et al. Ten-year trends in the incidence, treatment, and outcome of Q-wave myocardial infarction. Am J Cardiol 2000;86:730-5.

6 Goff DC Jr, Howard G, Wang CH, et al. Trends in severity of hospitalized myocardial infarction: The atherosclerosis risk in communities (ARIC) study, 1987-1994. Am Heart J 2000;139:874-80.

7 Hellermann JP, Reeder GS, Jacobsen SJ, et al. Longitudinal trends in the severity of acute myocardial infarction: a population study in Olmsted county, Minnesota. Am J Epidemiol 2002;156:246-53.

8 McGovern PG, Jacobs DR Jr, Shahar E, et al. Trends in acute coronary heart disease mortality, morbidity, and medical care from 1985 through 1997: The Minnesota heart survey. Circulation 2001;104:19-24.

9 Rosengren A, Thelle DS, Koster $M$, et al. Changing sex ratio in acute coronary heart disease: data from Swedish national registers 1984-99. J Intern Med 2003;253:301-10.

10 Rosen M, Alfredsson L, Hammar N, et al. Attack rate, mortality and case fatality for acute myocardial infarction in Sweden during 1987-95: results from the national AMI register in Sweden. J Intern Med 2000;248:159-64.

11 Capewell S, Maclntyre K, Stewart S, et al. Age, sex, and social trends in outof-hospital cardiac deaths in Scotland 1986-95: a retrospective cohort study. Lancet 2001;358:1213-7.

12 Tunstall-Pedoe $\mathbf{H}$, Vanuzzo $D$, Hobbs $M$, et al. Estimation of contribution of changes in coronary care to improving survival, event rates, and coronary heart disease mortality across the WHO MONICA project populations. Lancet 2000;355:688-700.

13 Kuulasmaa K, Tunstall-Pedoe H, Dobson A, et al. Estimation of contribution of changes in classic risk factors to trends in coronary-event rates across the WHO MONICA project populations. Lancet 2000;355:675-87.

14 Unal B, Critchley JA, Capewell S. Explaining the decline in coronary heart disease mortality in England and Wales between 1981 and 2000. Circulation 2004;109:1101-7.

15 Molarius A, Parsons RW, Dobson AJ, et al. Trends in cigarette smoking in 36 populations from the early 1980s to the mid-1990s: findings from the WHO MONICA project. Am J Public Health 2001;91:206-12.

16 Silventoinen K, Sans S, Tolonen H, et al. Trends in obesity and energy supply in the WHO MONICA project. Int J Obes Relat Metab Disord 2004;28:710-8. 
17 Yusuf S, Pearson $M$, Sterry $H$, et al. The entry ECG in the early diagnosis and prognostic stratification of patients with suspected acute myocardial infarction. Eur Heart J 1984;5:690-6.

18 DeWood MA, Spores J, Hensley GR, et al. Coronary arteriographic findings in acute transmural myocardial infarction. Circulation 1983;68:139-49.

19 DeWood MA, Stifter WF, Simpson CS, et al. Coronary arteriographic findings soon after non-Q-wave myocardial infarction. N Engl J Med 1986;315:417-23.

20 Hasdai D, Behar S, Wallentin L, et al. A prospective survey of the characteristics, treatments and outcomes of patients with acute coronary syndromes in Europe and the Mediterranean basin: the Euro heart survey of acute coronary syndromes (Euro heart survey ACS). Eur Heart $J$ 2002;23:1190-201.

21 Hasdai D, Behar S, Boyko V, et al. Cardiac biomarkers and acute coronary syndromes: the Euro heart survey of acute coronary syndromes experience. Eur Heart J 2003;24:1189-94.

22 Salomaa V, Miettinen H, Palomaki P, et al. Diagnostic features of acute myocardial infarction-changes over time from 1983 to 1990: results from the FINMONICA AMI register study. J Intern Med 1995;237:151-9.

23 Abildstrom SZ, Rasmussen S, Madsen M. Significant decline in case fatality after acute myocardial infarction in Denmark: a population-based study from 1994 to 2001. Scand Cardiovasc J 2002;36:287-91.

24 Khot UN, Khot MB, Bajzer CT, et al. Prevalence of conventional risk factors in patients with coronary heart disease. JAMA 2003;290:898-904.

25 Hsia J, Aragaki A, Bloch $M$, et al. Predictors of angina pectoris versus myocardial infarction from the women's health initiative observational study. Am J Cardiol 2004;93:673-8.

26 Herlitz J, Karlson BW, Lindqvist J, et al. Prognosis during five years of followup among patients admitted to the emergency department with acute chest pain in relation to a history of hypertension. Blood Press 1998;7:81-8.

27 Kennon S, Barakat K, Suliman A, et al. Influence of previous aspirin treatment and smoking on the electrocardiographic manifestations of injury in acute myocardial infarction Heart 2000;84:41-5.
28 Barbash GI, White HD, Modan M, et al. Significance of smoking in patients receiving thrombolytic therapy for acute myocardial infarction: experience gleaned from the international tissue plasminogen activator/streptokinase mortality trial. Circulation 1993;87:53-8.

29 Barbash GI, Reiner J, White HD, et al. Evaluation of paradoxic beneficial effects of smoking in patients receiving thrombolytic therapy for acute myocardial infarction: mechanism of the "smoker's paradox" from the GUSTO-I trial, with angiographic insights. Global utilization of streptokinase and tissue-plasminogen activator for occluded coronary arteries. J Am Coll Cardiol 1995:26:1222-9.

30 Grines CL, Topol EJ, O'Neill WW, et al. Effect of cigarette smoking on outcome after thrombolytic therapy for myocardial infarction. Circulation 1995;91:298-303.

31 Fuster V, Chesebro JH, Frye RL, et al. Platelet survival and the development of coronary artery disease in the young adult: effects of cigarette smoking, strong family history and medical therapy. Circulation 1981;63:546-51.

32 FitzGerald GA, Oates JA, Nowak J. Cigarette smoking and hemostatic function. Am Heart J 1988;115:267-71.

33 Hasdai D, Lerman A, Rihal CS, et al. Smoking status and outcome after primary coronary angioplasty for acute myocardial infarction. Am Heart J 1999; 137:612-20.

34 Jousilahti $\mathbf{P}$, Tuomilehto J, Vartiainen E, et al. Body weight, cardiovascular risk factors, and coronary mortality: 15-year follow-up of middle-aged men and women in eastern Finland. Circulation 1996:93:1372-9.

35 Wolk R, Berger P, Lennon RJ, et al. Body mass index: a risk factor for unstable angina and myocardial infarction in patients with angiographically confirmed coronary artery disease. Circulation 2003;108:2206-11.

36 Majahalme SK, Smith DE, Cooper JV, et al. Comparison of patients with acute coronary syndrome with and without systemic hypertension. Am J Cardiol 2003;92:258-63

37 Aursnes I, Landmark K. More non-Q-wave myocardial infarctions but similar infarct sizes in patients with hypertension. Blood Press 2000;9:98-103.

38 Evans A, Tolonen $\mathrm{H}$, Hense $\mathrm{HW}$, et al. Trends in coronary risk factors in the WHO MONICA project. Int J Epidemiol 2001;30(suppl 1):S35-40.

\section{IMAGES IN CARDIOLOGY}

\section{An unusual case of right ventricular dilatation}

A 19 year old woman was admitted with cough, dyspnoea, pleuritic chest pain, tachycardia, and hypoxia 20 weeks after the birth of her first child. Chest $x$ ray findings were unremarkable. Echocardiography (panel A) revealed pronounced right ventricular dilatation, severe tricuspid regurgitation, and a right ventricular systolic pressure of $70 \mathrm{~mm} \mathrm{Hg}$. Initially pulmonary embolism was suspected. Computed tomographic (CT) pulmonary angiography, however, showed no evidence of pulmonary embolism although high resolution CT images revealed diffuse bilateral air space shadowing (panel B). Avian proteins antibodies were strongly positive and on further questioning the patient admitted to keeping over 50 parakeets in her home. Her right ventricular dilatation and pulmonary hypertension resolved following steroid treatment. In summary, extrinsic allergic alveolitis is a rare but important cause of right ventricular dilatation and pulmonary hypertension.

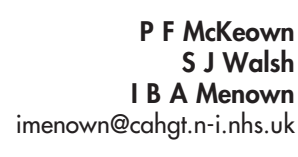

P F McKeown @cahgt.n-i.nhs.uk
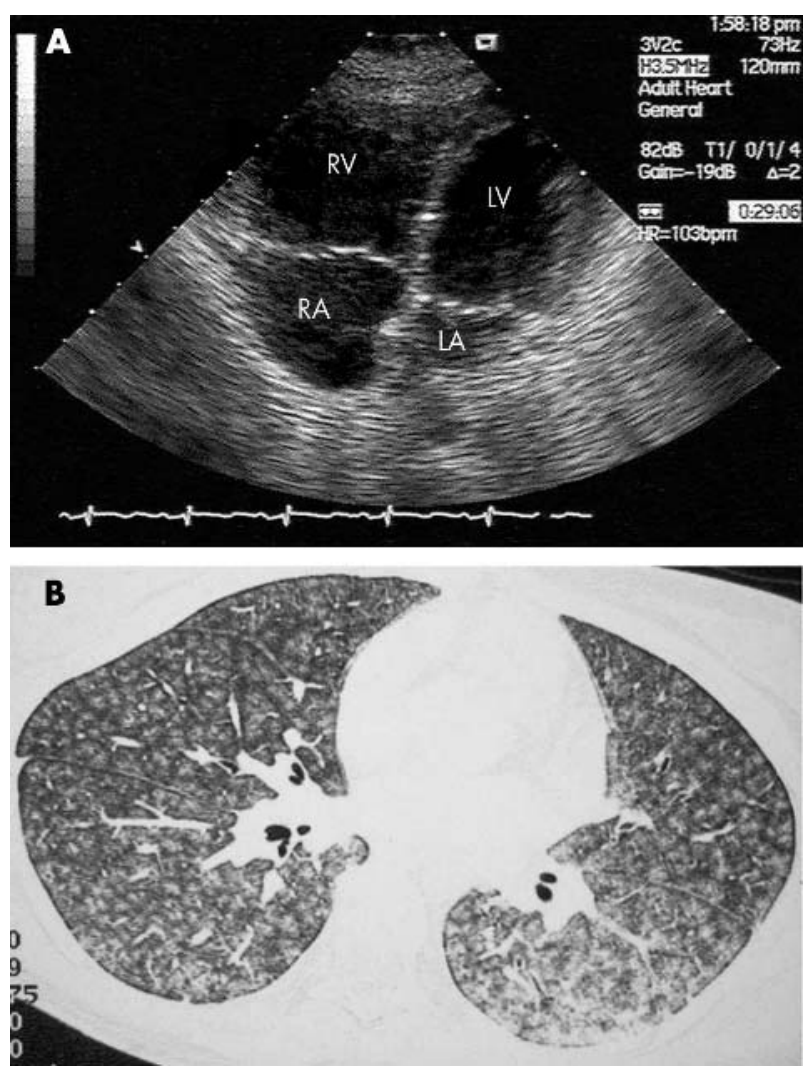

(A) Apical four chamber view echocardiogram showing severe right ventricular dilatation. (B) High resolution CT scan of chest. Bilateral air space shadowing is present with sparing of apical segments. 